\title{
Localization of Industry and Vertical Disintegration
}

\author{
Thomas J. Holmes* \\ Research Department \\ Federal Reserve Bank of Minneapolis \\ Minneapolis, MN 55480 \\ email: tjh@res.mpls.frb.fed.us
}

April 1995

\begin{abstract}
This paper considers the argument of Marshall that concentration of industry at a single location allows for a finer division of labor in the industry than would be possible if the industry were diffused over a wide area. I use Census data on manufacturing plants to examine the relationship between localization of industry and vertical disintegration. I find that establishments located near other establishments within the same industry tend to make more intensive use of purchased inputs than establishments without own-industry neighbors. This relationship only holds among industries that are geographically concentrated; having neighbors makes no difference in geographically dispersed industries. I argue that this pattern is consistent with a model in which increased opportunity for specialization is the reason some industries localize.
\end{abstract}

\footnotetext{
${ }^{*}$ The views expressed herein are those of the author and not necessarily those of the Federal Reserve Bank of Minneapolis or the Federal Reserve System. I am grateful to Pete Klenow, Jim Schmitz, and seminar participants at the Federal Reserve Bank of Minneapolis and New York University for helpful comments.
} 


\section{Introduction}

One of the central principles in economics is that more specialization is possible in a large economy than in a small one. This point was made by Adam Smith (1776, p. 21) when he wrote, "The division of labor is limited by the extent of the market."

Marshall (1920) applied this principle to explain why some industries are localized. A localized industry is one in which employment in the industry tends to be concentrated at particular points rather than being spread out over wide areas. Familiar examples of localized industries include the automobile industry in Detroit and the semiconductor industry in Silicon Valley. Marshall (1920, p. 271) argued that concentrating employment at a particular location spawns "subsidiary industries devoting themselves to one small branch of the process of production." In other words, it allows firms to emerge that specialize in producing particular intermediate inputs for the industry.

There are a fair number of anecdotes and case studies that illustrate how vertical disintegration can emerge in an area where an industry is localized. ${ }^{1}$ A classic example is the 19th century small-arms industry in Birmingham, England, described by Allen (1929) (also cited by Stigler (1951)):

The master gun-maker - the entrepreneur — seldom possessed a factory...his function was to acquire semi-finished parts and to give these out to specialized craftsmen who undertook the assembly and finishing. He purchased materials from the barrel-makers, lock-makers, sight-stampers, triggermakers, ramrod-forgers, gun furniture makers...All of these were independent manufacturers.

This paper considers two questions. First, do manufacturing plants located within an area where their industry is concentrated tend to make more use of outside suppliers for intermediate goods than do factories located outside the point of concentration? Marshall's ideas seem relevant for the 19th century gun industry in Birm-

\footnotetext{
${ }^{1}$ There are studies of the aircraft industry in Southern California (Scott and Mattingly (1989)), the printed circuits industry in Southern California (Scott and Kwok (1989)), and a variety of industries concentrated in New York (Hall (1959) and Lichtenberg (1960)). All of these studies document the importance of specialized suppliers in industrial districts. (Additional references can be found in Scott (1983).)
} 
ingham. Are they relevant in the manufacturing sector today? The results of this paper suggest that the answer is yes. I consider U.S. Census data on purchased inputs of manufacturing establishments. This is the value of intermediate goods purchased from outside suppliers (as opposed to intermediate goods produced internally). I construct a measure of own-industry neighboring employment for each manufacturing establishment by counting up the employment of all other plants in the same industry located within 50 miles of the establishment. I show that establishments with a large amount of own-industry neighboring employment tend to more intensively use purchased inputs compared with establishments in the same industry with little own-industry neighboring employment. I interpret this as evidence of greater vertical disintegration of industry in areas where industry concentrates.

As for the second question, this paper asks whether there is any evidence that increased opportunity for specialization is a factor that explains why some industries are localized. There are a variety of other reasons why industry might concentrate in a particular place. The most obvious reason is that an area might have unique climate conditions or natural resources that make the area particularly suitable for an industry. Surely the existence of special agricultural conditions in California is the primary factor explaining the location of the wine industry within this state. In the wine region there are numerous specialized input suppliers, including a type of business called "mobile wine bottling." Nevertheless, the high degree of specialization that has emerged here can fairly be judged as a consequence of the concentration of this industry in California, not a cause. Another alternative explanation for localization is possible information spillovers across firms. As Marshall (1920, p. 271) explained, ideas are "in the air" in industrial districts. ${ }^{2}$ Yet another possible explanation (also discussed by Marshall) has to do with labor-market mobility. ${ }^{3}$

The answer to the second question is that I do find some preliminary evidence that suggests that increased opportunity for specialization plays a role in the localization of industry. The nature of the evidence is a pattern I obtain when I distinguish between industries that are geographically concentrated and industries that are ge-

\footnotetext{
${ }^{2}$ Jaffe, Trajtenberg, and Henderson (1993) have recently provided evidence that geographical proximity is important for the flow of ideas. See also Glaeser et al. (1992).

${ }^{3}$ Krugman (1991, chapter 2) surveys the various arguments for why industry might localize.
} 
ographically dispersed. I use the measure of geographic concentration of industry recently proposed by Ellison and Glaeser (1994) to classify industries. I find that the relationship between purchased-inputs intensity and own-industry neighboring employment depends on how geographically concentrated the industry is.

The results are easier to keep track of if I explain them in terms of actual industries. The women's hosiery industry is a good example of a geographically concentrated industry because the state of North Carolina contains 62 percent of the nation's employment in that industry. For establishments of this industry located within North Carolina, the value of purchased inputs averages 54 percent of the value of final production; outside this state it averages only 40 percent. My empirical analysis indicates that this positive relationship between purchased-inputs intensity and ownindustry neighboring employment is also true on average among other geographically concentrated industries.

The envelope industry is a good example of a geographically dispersed industry. According to the Census data, there are 298 plants in the industry scattered across 40 states. Even though the industry is relatively dispersed, there are pockets of concentration in the industry. For example, there are some 30 plants in the New York metropolitan region, 26 in Los Angeles, and 17 in Chicago. For this industry there appears to be little difference on average in the purchased-inputs intensity of plants with many neighbors, such as those in New York and Chicago, and the intensity of plants with few neighbors, such as the 3 plants in Iowa. My empirical analysis indicates that this weak to nonexistent relationship between purchased-inputs intensity and neighboring employment is also true on average among other geographically dispersed industries.

Why does this pattern in the data have anything to suggest about the role specialization plays in the localization of industry? My argument is that this pattern is consistent with a simple model where there are two kinds of industries distinguished by whether the intermediate goods to the industry are nontradeable or tradeable.

In the first type of industry, the intermediate inputs for the industry are nontradeable across locations. With this type of industry it is efficient for the industry to be geographically concentrated since this is the only way specialization is possible 
given the nontradeable nature of the intermediate inputs. Even though most plants in such industries will be located in areas where the industry is concentrated, there will usually be a few plants in the industry located in isolated areas because of various specific supply and demand factors within these areas. Because intermediate inputs are nontradeable, the plants in isolated areas have no choice but to be vertically integrated. In the localized areas, vertical disintegration is possible and desirable. In the hosiery industry, the plants located outside of North Carolina generally undertake the knitting stage and the dying and finishing stages within the same establishment. But in North Carolina, a sizeable percentage of these operations are conducted within different plants. ${ }^{4}$

In the second type of industry, intermediate inputs are tradeable across locations. There is no efficiency gain to concentrating industry at a single location, so plants in the industry are scattered throughout the nation. By chance it may happen that there are pockets of concentration in the industry. However, a plant in an isolated location will be no more vertically integrated than a plant in a concentrated location. Since intermediate goods are tradeable across locations, a plant in an isolated location is free to specialize. For example, in the envelope industry intermediate inputs include paper and adhesives. These inputs are presumably tradeable, so that a plant in Iowa can specialize to the same degree as a plant in the New York metropolitan region.

This simple model with two kinds of industries is consistent with the pattern in the data. A simple model in which localization of industry is determined solely by endowments in natural resources would not imply this pattern. Nor would a simple model in which localization occurs because of knowledge spillovers imply this pattern. Clearly these alternative explanations for localization play important roles in accounting for why certain industries localize. But the pattern I find in the data suggests that increased opportunity for specialization is also a factor.

Understanding the source of any increasing returns in an economy that are gained

\footnotetext{
${ }^{4}$ North Carolina establishments account for 82 percent of all shipments of women's hosiery and pantyhose shipped in the greige condition, i.e., unbleached and undyed. This figure is substantially higher than North Carolina's share of industry employment (62 percent) and shipments of women's finished panty hose (57 percent). My rough calculations with the Census data indicate that for about 25 percent of the pairs of panty hose made in North Carolina, the knitting and finishing stages are conducted in separate establishments.
} 
from concentrating employment at a location is of fundamental interest. It lies at the heart of many discussions in trade policy and state and local development policy. To see the significance for trade policy, consider what happens when a country such as the United States becomes open to trade with a country such as Mexico. A question that is of interest to many is whether manufacturing will move to Mexico to take advantage of lower wages. To the extent that geographic proximity to specialized suppliers is important and to the extent that a network of suppliers takes time to build up (or down), there may be some glue that keeps an industry from a leaving an area in which a network of specialized suppliers has already been established.

In what remains of the introduction, I briefly outline the paper and mention some of the relevant literature.

\section{Outline of the Paper}

Section 2 of this paper contains a theoretical analysis. My model follows the models of Abdel-Rahman (1988), Abdel-Rahman and Fujita (1990), and Ciccone and Hall (1993), which use the Dixit and Stiglitz (1977) model of monopolistic competition to formalize Marshall's insight that greater concentration of employment increases the number of specialized intermediate producers that can break even. My point of departure from the previous work is to introduce into a model a second technology for producing intermediate inputs internally that is an alternative to the technology for producing the goods for the market. This extension makes it possible to examine the issue of which goods are produced internally and which goods are produced in the market by specialized producers. ${ }^{5}$

Section 3 of this paper sets up the data set. My handling of the geographic data gets around problems that have plagued previous work of how to deal with the arbitrary boundaries of the geographic units for which data are collected. A number of studies have examined the relationship between productivity and concentration of

\footnotetext{
${ }^{5}$ There are a number of theoretical papers with the result that equilibrium vertical integration declines as the size of the economy increases. Perry (1989) surveys several such papers, including Stigler (1951), Perry and Groff (1982), Vassilakis (1986). The papers of Locay (1990) and Goodfriend and McDermott (1995) obtain the closely related result that there is a shift from home production to market production as the size of an economy increases. The technology considered in this paper is very similar to the technology in the model of Goodfriend and McDermott (1995).
} 
industry (for example, Henderson (1986)). Typically, studies have used employment in a city as a measure of concentration. But as Ciccone and Hall (1993) point out, deciding that San Francisco and Oakland are the same or different cities may have an important effect on the results. Ciccone and Hall (1993) propose getting around these problems by using density - they divide employment in a geographic unit by the area of the unit. A problem with this approach is that employment in an area may be small in an absolute sense, but density may be high because the area of the geographic unit is small. For example, an isolated location in Wyoming might have a high population density if the geographic unit is the land under a farmhouse containing a family with ten children. This study avoids this difficulty by holding fixed the absolute size of the geographic unit (a circle of radius 50 miles). Approximate longitude and latitude coordinates for all manufacturing establishments are obtained, and these are used to identify the neighbors of a plant.

Section 4 presents the empirical results. The analysis uses purchased inputs as a percentage of the value of output to measure vertical disintegration. The idea of using such a measure dates to Adelman (1955).

\section{Theory}

The first part of this section describes a model in which there is a single final good and a single location. Intermediate inputs can be purchased through the market or produced internally. The second part solves for the equilibrium. The third part discusses the implications of the analysis for Census data on purchased inputs. The fourth and final part extends the analysis to the case of many final goods and many locations. This last part discusses the issue of why some industries are concentrated and others are dispersed.

\subsection{The Model}

There is a single final good in the economy and a single location. The economy is populated by $N$ individuals, each endowed with a single unit of labor.

The production function for the final good is

$$
f(L, M)=L^{1-\alpha} M^{\alpha},
$$


where $L$ is the amount of labor that is directly applied to the production of the final good and $M$ is a composite intermediate input. The composite intermediate good is produced by combining a continuum of differentiated inputs indexed by $t$ on the unit interval $[0,1]$. Let $x(t)$ denote the amount of input $t$ used. The production function for the composite intermediate good is

$$
M=\left[\int_{0}^{1} x(t)^{\frac{1}{\mu}} d t\right]^{\mu},
$$

where $\mu>1$. This production function exhibits constant returns to scale and has constant elasticity of substitution. The assumption that $\mu>1$ is equivalent to the assumption that the elasticity of substitution $\sigma=\frac{\mu}{\mu-1}$ is greater than one. ${ }^{6}$

There are two ways to produce the differentiated intermediate inputs. The first way is denoted the internal technology. An intermediate input produced in this way is manufactured in the same factory where it is ultimately used to produce the final product. The labor required to produce $x(t)$ units of the input in this way is $\gamma x(t)$ units of labor. In other words, the cost per unit is $\gamma$ units of labor, independent of the scale of operation. Assume that $\gamma>\mu$. Since $\mu>1$, this implies that $\gamma>1$.

The second way to produce a differentiated intermediate input $t$ is to set up a specialized factory that produces only input $t$. Setting up this specialized factory entails a fixed cost of $\theta$ units of labor. The marginal cost of producing one more unit equals one unit of labor. This production process is called the specialist technology. The specialist technology has lower marginal labor cost than the internal technology ( since $1<\gamma)$. It has the disadvantage of a higher fixed $\operatorname{cost}($ since $\theta>0)$.

At this point it is natural to ask, Why can't a specialist producer employ the first technology? Why can't a final-good producer use the second technology? These assumptions can be motivated by making some small changes in the model. Suppose there is a small transportation cost to move an intermediate good from an intermediate-good factory to a final-good factory. In this case, even if it were possible for a specialist producer to use the first technology to produce an intermediate input, no final-good producer would ever hire such a specialist to use this technology. Producing the input internally has the advantage of avoiding the transportation cost.

\footnotetext{
${ }^{6}$ This is a standard assumption in the Dixit-Stiglitz monopolistic competition literature and is needed for existence of equilibrium. Demand is inelastic without this assumption.
} 
And there is no disadvantage since the average production cost is the same for internal and external production (because of the constant returns to scale). The story is different for the second technology. Suppose a final-good maker uses the second technology to produce an intermediate input that it consumes in its plant. Because of the increasing returns to scale with this technology, the final-good maker producing the input only for its own needs has a higher average cost than a specialist producer supplying the entire market for the input. Of course, this wouldn't be true if the entire labor force in the economy were concentrated into one huge establishment. But this possibility can be eliminated by assuming there is some sort of managerial diseconomies of scale that prevent an establishment from becoming so large. In particular, it can be assumed that the employment of each establishment is constrained to be of measure zero, so there is a continuum of establishments, each of infinitesimal size.

\subsection{Equilibrium}

The definition of equilibrium and the solution follows Dixit and Stiglitz (1977) and the subsequent literature. The numeraire is the final good. Let $w$ be the price of a unit of labor in terms of the final good. Let $z$ denote the measure of the set of intermediate goods that are available from specialist producers. Given the symmetry of the intermediate goods, it can be assumed that the specialist intermediate goods lie in the interval $[0, z]$ while the remaining, internally produced goods lie in the interval $(z, 1]$. Let $p(t)$ denote the price of specialist good $t \in[0, z]$.

The problem of a final-good producer is to choose an amount of direct labor $L$ and a vector of intermediate inputs to maximize profits:

$$
\max _{x(\cdot)} L^{1-\alpha}\left[\int_{0}^{1} x(t)^{\frac{1}{\mu}} d t\right]^{\mu \alpha}-\int_{0}^{z} p(t) x(t) d t-\int_{z}^{1} \gamma w x(t) d t .
$$

Here the first term is the output of the final good. The second term is the payments to specialist producers for the goods $[0, z]$. The third term is the cost of producing intermediate goods $(z, 1]$ internally. (Each unit requires $\gamma$ units of labor and each labor unit costs $w$ units of the final good.) Note that in (3), it is implicitly assumed that $p(t) \leq \gamma w$ for all specialist intermediate goods $t$. This will be necessary in equilibrium because final-good producers have the option of producing any intermediate 
good internally at a cost per unit of $\gamma w$ units of the final good.

Assumptions will be made below to ensure that in equilibrium there is only a single producer of each specialist good $t \in[0, z]$. The objective function of the finalgood producers given by (3) implies a derived demand curve for intermediate goods that has constant elasticity. Standard arguments show that profit maximization by intermediate goods producers implies that the price is a constant markup equal to $\mu$ over marginal cost; i.e., $p(t)=\mu w$ for $t \in[0, z]$. There is free entry into intermediategood production, and this implies a zero-profit condition

$$
\mu w x_{M}-w x_{M}-w \theta=0
$$

where $x_{M}$ is the equilibrium output of a market intermediate good. In (4), the first term is revenue. The second is variable cost. (Recall the marginal cost is one unit of labor.) The third is the value of the fixed cost. Solving the zero-profit condition yields the equilibrium level of output for specialist goods:

$$
x_{M}=\frac{\theta}{\mu-1} .
$$

Maximization of profit (3) yields the condition that the marginal rate of technical substitution between specialist and internal inputs equal the ratio of the factor prices,

$$
\frac{x_{M}^{\frac{1-\mu}{\mu}}}{x_{I}^{\frac{1-\mu}{\mu}}}=\frac{\mu w}{\gamma w} .
$$

Solving for $x_{I}$ in terms of $x_{M}$ yields

$$
x_{I}=\left(\frac{\mu}{\gamma}\right)^{\frac{\mu}{\mu-1}} \cdot x_{M} .
$$

The final condition for equilibrium is that demand equal supply in the labor market. Given the Cobb-Douglas production function for final output, it is straightforward to show that the equilibrium share of the labor force directly used in the production of the final good is $1-\alpha$; i.e. $L=(1-\alpha) N$. The rest of the labor force $\alpha N$ is allocated to the production of intermediate inputs,

$$
z\left(x_{M}+\theta\right)+(1-z) x_{I} \gamma=\alpha N
$$


The first term of the left-hand side here is the labor requirement of specialist producers. The second term is the labor requirement for internal production.

Plugging (5) and (7) into (8) leads to the solution for the equilibrium number of market intermediate goods $z^{e}$. The particular interest here is how this varies as a function of the size $N$ of the economy. There are two critical levels of $N$, defined by

$$
N^{\prime}=\frac{\gamma \theta}{\alpha(\mu-1)}\left(\frac{\mu}{\gamma}\right)^{\frac{\mu}{\mu-1}}
$$

and

$$
N^{\prime \prime}=\frac{\gamma \theta}{\alpha(\mu-1)}\left(\frac{\mu}{\gamma}\right) .
$$

Assume that $N \leq N^{\prime \prime}$. The equilibrium number of market equilibrium goods is given by

$$
\begin{array}{cc}
z^{e}=0, & N \leq N^{\prime} \\
z^{e}=\frac{\left(N-N^{\prime}\right)}{N^{\prime \prime}-N^{\prime}}, & N^{\prime}<N \leq N^{\prime \prime} .
\end{array}
$$

This function is illustrated in Figure 1. For $N$ smaller than $N^{\prime}$, the economy is too small for any specialist input producers to emerge. At the critical point $N^{\prime}$, specialist input producers begin to appear, and the number of different specialist goods $z^{e}$ increases as $N$ increases. Final-good producers substitute internal production of intermediate inputs with less costly inputs manufactured by specialist producers. When $N$ is as high as $N^{\prime \prime}$, all of the intermediate inputs $t \in[0,1]$ are produced by specialists. $^{7}$

This simple model illustrates Adam Smith's (1776) point that greater specialization is possible in a larger economy. In a small economy, $N<N^{\prime}$, each factory is completely integrated, producing the entire range of intermediate inputs as well as the final good under the same roof. As $N$ increases, the range of activities undertaken by a final-good factory decreases as the tasks of making specific intermediate inputs are spun off to specialists. An increase in $N$ results in vertical disintegration. As

\footnotetext{
${ }^{7}$ I have not worked out the case of $N>N "$. This case is complicated because in it intermediategood producers can obtain positive profits. There exists a specialized producer for each product on the entire range $[0,1]$. If a new firm enters, it has to compete with an existing producer rather than add a new product not available on the market. This problem does not arise in the literature because the set of potential products is usually assumed to be unbounded. I can't assume that here because given the existence of the second, constant returns to scale technology, there would not exist a solution to the final-good producer's problem (3). (Profit could alway be increased by increasing the range of intermediate goods used.)
} 
Adam Smith (1776) pointed out, the increased division of labor afforded by larger $N$ increases per capita income (in this case equal to the wage $w$ ).

\subsection{Implications for Census Data}

The previous subsection showed how an increase in the size of the economy leads to vertical disintegration. This subsection considers the implications of this process for data that are collected by the Census. This subsection defines some variables that are theoretical analogs of variables defined by the Census. It considers the effect on these variables of increasing the size $N$ of the economy.

To begin with, assume that the Census classifies producers of the final good in a separate industry from specialist intermediate-input producers. This is a reasonable assumption for the four-digit level industry data that I look at because the Census claims that most transactions involve establishments in different four-digit industries. ${ }^{8}$ The Census collects data on the value of production of the final-good producers. Let output denote the level of production of the final good. Since the final good is the numeraire, output is also the value of production of the final good. Note that since labor is the only ultimate factor of production in the economy (intermediate goods are produced by labor), the entire value of production of the final good goes to labor; i.e., output $=w N$.

The Census collects data on the number of employees working at each establishment. For $N$ less than $N^{\prime}$, everybody in the economy works at a final-good plant, so employment in the final-good industry is $N$. For $N$ between $N^{\prime}$ and $N^{\prime \prime}$, the number of employees working at final-good-producing establishments is

$$
\text { employment }=L+(1-z) \gamma x_{I}
$$

Here the first term $L$ accounts for the employees directly engaged in the production of the final good, and the second term accounts for the employees that make intermediate goods through the internal process. Consider what happens to employment as the

\footnotetext{
${ }^{8}$ According to the Census (1987 Census of Manufactures, Subject Series, General Summary, p. xxv), "The aggregates of the cost of materials ... for industry groups and all manufacturing industries include large amounts of duplication since the products of some industries are used as materials by others. With some important exceptions ... this is not significant within individual four-digit industries."
} 
size $N$ of the economy increases. Direct labor $L$ is a constant fraction of total labor, $L=(1-\alpha) N$, so the first term increases with $N$. But the second term decreases with $N$ as fewer intermediate goods are produced internally and more are produced by outside specialists. For $N$ between $N^{\prime}$ and $N^{\prime \prime}$, the net effect of a change in $N$ on employment is positive if and only if the following condition holds:

$$
\alpha<1-\left(\frac{\mu}{\gamma}\right)^{\frac{1}{\mu-1}}
$$

For example, if $\mu=1.5$ (implying a 50 percent markup over cost by specialists) and if $\gamma=2$ (so the internal marginal cost is twice the specialist marginal cost), then the condition is $\alpha<.43$. The condition requires that $\alpha$, the share of income going to intermediate-good production, not be too big. Assume that the condition holds. Under this condition, an increase in $N$ increases employment as well as output. To the extent the economies vary in $N$, all else fixed, there is a positive relationship between employment in the final-good industry and output in the final-good industry.

I make assumption (13) to ensure that an economy with more employees in the final-good and intermediate-input sectors combined (i.e., $N$ ) has more employees in the final-good industry by itself (i.e., the Census variable employment). This implication of (13) seems plausible. As an alternative strategy, I could assume that the Census definition of the industry includes the specialist intermediate-input producers as well as the final-good producers. (For example, the women's hosiery industry ( $\mathrm{SIC}=2251$ ) includes establishments making hosiery in the greige condition (unbleached and undyed) as well as establishments making finished hosiery.) If the industry is defined to include the intermediate-good producers, the Census employment variable would simply equal $N$, and so it would obviously increase in $N$ without having to make assumption (13).

The Census collects data on intermediate inputs that are purchased from outside suppliers. Define the variable purchased inputs to be the value of production of specialist factories. This equals

$$
\text { purchased inputs }=z x_{M} \mu w \text {. }
$$

Recall that there are $z$ specialist factories and each sells $x_{M}$ units at a price of $\mu w$. The measure of purchased-inputs intensity is purchased inputs as a percentage of 
output. Formally, it is

$$
\begin{aligned}
\text { purchased-inputs intensity } & \equiv 100 \cdot \frac{\text { purchased inputs }}{\text { output }} \\
& =100 \cdot \frac{z x_{M} \mu w}{w N}=100 \cdot \frac{z}{N} \cdot x_{M} \mu .
\end{aligned}
$$

Recall that output equals total wages $w N$ in the economy. It is multiplied by 100 to convert the fraction into a percentage. For $N$ between $N^{\prime}$ and $N^{\prime \prime}$, this intensity measure strictly increases in $N$ ( since $z / N$ strictly increases while $x_{M}$ is a constant). For $N$ less than $N^{\prime}$, the measure is constant at zero.

This section has defined a measure of purchased-inputs intensity and has shown that intensity increases in the size $N$ of the economy (for $N>N^{\prime}$ ). Under condition (13), employment in the final-good industry increases with $N$. Given this condition and to the extent that economies vary in $N$, an increase in employment in the finalgood industry will be associated with an increase in purchased-inputs intensity.

\subsection{Many Final Goods and Many Areas}

Now the case of many industries and many areas is considered. In this setting, some industries will be dispersed and some industries will concentrate at a particular location. This subsection shows that the patterns in the data for dispersed industries will be different than the patterns in the data for geographically concentrated industries.

The point can be made with a particular numerical example. There are two areas and four final goods. A unit measure of individuals live in each area. All individuals in the economy have the same Cobb-Douglas utility function for the four final goods,

$$
u\left(q_{1}, q_{2}, q_{3}, q_{4}\right)=q_{1}^{\frac{1}{4}} \cdot q_{2}^{\frac{1}{4}} \cdot q_{3}^{\frac{1}{4}} \cdot q_{4}^{\frac{1}{4}}
$$

With this utility, individuals allocate one-fourth of their income to the purchase of each final good.

Each final good $i$ is produced with intermediate inputs that are specific to industry $i$. That is, intermediate inputs are differentiated by destination industry $i$ in addition to type $t$ defined earlier. For simplicity, assume that the four different industries have the same parameters $\mu, \theta$, and $\gamma$. (In general, these might vary by industry, but that

won't be necessary here.) Assume that $\mu, \theta$, and $\gamma$ are such that $N^{\prime}<\frac{1}{2}<N^{\prime \prime}$, where 
$N^{\prime}$ and $N^{\prime \prime}$ are defined by $(9)$ and (10). (The motivation for this assumption will be clear in a moment.)

It is costless to transport final goods between the areas. The industries differ in only one way. It is impossible to transport the intermediate inputs of industry 1 and 2 across areas; intermediate inputs are nontradeable. For industries 3 and 4, it is costless to transport intermediate inputs across areas; intermediate inputs are tradeable.

The equilibrium for this simple model is easy to solve. With two areas and a unit measure of individuals in each area, the total measure of individuals in the economy is two. Given the Cobb-Douglas utility function, one-fourth of the economy-wide labor force works in each industry, so the work force in industry $i$ (including employees in specialist factories) is $N_{i}=1 / 2$. Since $1 / 2>N^{\prime}$ by assumption, $N_{i}>N^{\prime}$; i.e., the work force in each industry is sufficiently large to support some specialist input factories. (See Figure 1.)

What is the pattern of industry location in this economy? Industries 1 and 2 have nontradeable intermediate inputs, so the work force in each of these industries is concentrated at a particular location. Suppose that the areas are labeled, so that industry 1 locates in area 1 and industry 2 locates in area 2. Thus, in area 1, half of all the people work in final-good plants or specialist plants for industry 1. Similarly, in area 2 , half of all the people work in final-good or specialist plants for industry 2.

Industries 3 and 4 have tradeable intermediate inputs. The work force in these two industries can be scattered in any arbitrary way across the two areas.

Industries 3 and 4 can be classified as dispersed industries. Suppose that for a given dispersed industry, we were to compare production in this industry across the two areas. Let employment $t_{i a}$ equal the number of employees in plants producing final good $i$ in area $a$ (as in (12)), and analogously define purchased inputs sa and outputia. For industries 3 and 4, employment ia may vary across the areas a since the allocation is arbitrary. However, there will be no difference in the purchased inputs across areas. Since intermediate inputs are tradeable across areas, the organization of production is the same in each area.

Industries 1 and 2 are concentrated industries. As the model is presently stated, 
purchased-inputs intensity cannot be compared across areas because all production in industry 1 is in area 1 and all production in industry 2 is in area 2 . However, with slight modifications of the model, it is possible for there to be some amount of production in both areas for both industries. This can be accomplished by introducing aspects of local demand or local supply. For example, suppose individuals have an inelastic demand for $\epsilon$ units of locally produced final good 1 in addition to their demand for good 1 that is not constrained by its source. Similarly, assume individuals have an inelastic demand for $\epsilon$ units of locally produced final good $2 .{ }^{9}$ For $\epsilon$ arbitrarily small, the equilibrium is arbitrarily close to the original case, where $\epsilon=0$. Now, however, there is a small amount of production of final good 1 in area 2. Similarly, there is a small amount of production of final good 2 in area 1.

Now compare production in industry 1 across areas 1 and 2. The number of individuals in area 2 who work in industry 1 is close to zero. As can be seen in Figure 1 , this is too small to support the existence of any specialist input suppliers. Producers of final good 1 in area 2 are completely integrated; i.e., purchased inputs $s_{12}=0$. However, for $\epsilon$ close to zero, the work force in industry 1 in area 1 is approximately $1 / 2$ and as mentioned above, this is large enough to support some specialist input suppliers. Since a plant in area 2 producing final good 1 does not have access to specialist suppliers, it has higher cost than a plant in area 1 . To compensate for this higher cost, the price of good 1 produced in area 2 exceeds the price of good 1 produced in area 1 .

The discussion above presents a local-demand argument for why there might be some employment in both areas for final goods 1 and 2. An analogous local-supply argument can be given. Suppose there exists a small number of individuals in each area who are constrained to work in final-good industry 1, and assume that these individuals cannot migrate. (In the real world this might correspond to a family business that has been kept open for years, in which human capital specific to the industry is passed from generation to generation.) In equilibrium, employment in the industry will concentrate in area 1 , but there will be a small amount of employment

\footnotetext{
${ }^{9}$ To make this formal, let $q_{i}^{\text {local }}$ denote an amount of consumption of good $i$ produced locally and let $q_{i}$ denote additional consumption of good $i$ produced anywhere, $i=1,2$. Suppose consumers have utility $\tilde{u}\left(q_{1}^{\text {local }}, q_{2}^{\text {local }}, q_{1}, \ldots, q_{4}\right)=u\left(q_{1}, \ldots, q_{4}\right)$ given by (17) for $q_{1}^{\text {local }} \geq \epsilon$ and $q_{2}^{\text {local }} \geq \epsilon$ and $\tilde{u}\left(q_{1}^{\text {local }}, q_{2}^{\text {local }}, q_{1}, \ldots, q_{4}\right)=0$ if either $q_{1}^{\text {local }}<\epsilon$ or $q_{2}^{\text {local }}<\epsilon$.
} 
in area 2 . The wage paid these workers in area 2 will be lower than the wage in area 1 to compensate for the lower productivity in area 2 .

This subsection has made the following point: For some industries, nontradeable intermediate inputs are not a big deal. These industries will be geographically dispersed. For other industries, nontradeable inputs are a big deal, and these industries will be geographically concentrated. For dispersed industries, there may be variations in employment across areas, but these will not be associated with variations in purchased-inputs intensity. For concentrated industries, variations in industry employment across areas will be associated with differences in purchased-inputs intensity.

It is useful to consider the implications of an alternative model of industry location. Suppose that there are a large number of industries and locations, and to keep things simple, suppose that, as above, all industries have identical production parameters; i.e., the $\mu_{i}, \theta_{i}$, and $\gamma_{i}$ are the same for all $i$. Suppose that intermediate inputs are nontradeable for all the industries. Finally, suppose that the number of individuals $N_{i a}$ working in industry $i$ in area $a$ is exogenous. It may be helpful to think of this as determined by nature, i.e., following from the endowment of climate and natural resources in a particular area.

It is straightforward to show that $z_{i a}$, the equilibrium number of different specialist intermediate-input producers of industry $i$ located in area $a$, as a function of $N_{i a}$, follows the same formula (equation (11)) as in the one-final-good, one-area case. This is the relationship illustrated in Figure 1. Depending on the whims of nature, some industries will be geographically concentrated and others will be geographically dispersed. But for all industries, the relationship between $z_{i a}$ and $N_{i a}$ is the same. In other words, unlike the previous model of location, here there is no difference between concentrated and dispersed industries in the relationship between purchased-inputs intensity and neighboring employment.

\section{The Data}

This section discusses the data. The first subsection describes the variables collected by the Census. The second subsection explains the procedure I used to handle the 
geographic nature of the data set.

\subsection{The Variables Collected by the Census}

The data are from the 1987 Census of Manufactures (the most recent data available). These data are collected at the establishment level (a factory or plant at a particular location) as opposed to the firm level. Each establishment was asked to report information about the activity of the plant in 1987.

The key Census variable for my purposes is purchased inputs. ${ }^{10}$ This variable is the value of intermediate goods obtained from other establishments. According to the Census, "It includes the cost of materials or fuel consumed, whether purchased by the individual establishment from other companies, transferred to it from other establishments of the same company, or withdrawn from inventory during the year." 11 The variable purchased inputs has the following four components (and each component has the stated share of all purchased inputs for the entire manufacturing sector): (1) raw materials, semifinished goods, parts, and containers (87.8 percent); (2) resales, i.e., products bought and resold in the same condition (5.0 percent); (3) contract work, i.e., work done by others on materials or parts furnished by manufacturing establishments (3.2 percent); and (4) fuels consumed and purchased electric energy (4.0 percent).

A key focus of the theory is intermediate goods that are nontradeable. In that regard, an important component of purchased inputs is the third in the above list, contract work done by others on the establishment's materials. The case of a winery in California hiring a mobile bottler to bottle the wine (mentioned in the introduction) is an example of such contract work. Contract work such as this is not a tradeable input because of the costs involved in transporting a mobile bottling vehicle long distances. Note that while contract work is a small percentage (3.2 percent) over all industries combined, there is wide variation in this variable across industries and establishments. ${ }^{12}$

\footnotetext{
${ }^{10}$ The Census actually refers to this variable as cost of materials. For my purposes, it is convenient to rename the variable purchased inputs.

${ }^{11}$ Census of Manufacturers-Overview, 1987 Economic Censuses Technical Documentation, CDROM, Volume 1E, Part 1, p. XVII-10.

${ }^{12}$ For example, in the apparel two-digit industry (which is a heavily localized industry) contract
} 
There is one significant problem with the purchased-inputs variable. The variable does not include any business services that the establishment buys. ${ }^{13}$ For example, suppose the establishment hires an outside contractor to handle advertising or data processing. This will not be included in purchased inputs. This is unfortunate for my purposes since some of these business services are likely to be the kind of nontradeable intermediate inputs that this paper is all about. And business services are nonnegligible. (I estimate that the value of these services is 21 percent of the value of all the intermediate inputs. $)^{14}$

While the purchased-inputs variable is less than satisfactory, it is still possible to use this variable for scientific purposes. Consider the following extension of the model. Suppose that the set of all intermediate inputs is partitioned into two groups, measured intermediate inputs and unmeasured intermediate inputs. For example, suppose inputs $t \in[0, \zeta]$ (for some parameter $\zeta<1$ ) are the measured inputs and inputs $t \in(\zeta, 1]$ are the unmeasured inputs. Define the variable measured purchased inputs to be the value of production of specialist factories of inputs that are in the measured group. All the implications of the previous section regarding what happens to the purchased-inputs variable also hold for the measured-purchased-inputs variable. In what follows when I refer to purchased inputs, it is best to think of this as corresponding in the model to measured purchased inputs.

Two other Census variables are important in the analysis. The variable employment is the number of full- and part-time employees of the establishment in midMarch 1987. The variable that I call output is the receipts from sales of products that left the plant in 1987. (The Census calls this variable value of shipments.)

work makes up 17.0 percent of all purchased inputs.

${ }^{13}$ Ciccone and Hall (1993) point out that this feature of Census methodology limits the usefulness of using Census data to look at productivity. Value-added is defined by subtracting purchased inputs from the value of production (and correcting for a change in inventories). Census valueadded overstates true value-added because business services are not subtracted.

${ }^{14}$ Let $v_{N I P A}$ and $v_{C e n s u s}$ denote value-added from the National Income and Product Accounts and the Census. According to Census documents, $v_{N I P A} \approx v_{\text {Census }}-$ Business Services-IVA $+I B T$, where IVA is an inventory valuation adjustment found in the NIPA and IBT is indirect business taxes. Using figures for 1987 (in billions), $v_{N I P A}=853.6, v_{\text {Census }}=1165.7, I V A=-6.1$, and $I B T=41.6$. This yields an estimate of business services equal to 359.8 billion. The Census purchased inputs variable is 1319.8 for all of manufacturing. The value of all intermediate inputs including services is then 1679.6 billion. 


\subsection{Construction of the Data Set}

It is useful to begin by explaining what the procedure would be if ideal data were available. Ideal data would consist of the records for each establishment in the 1987 Census of Manufacturers. With these records, it would be possible to pinpoint the exact location (the longitude and latitude coordinates) of each establishment. Suppose a circle of a given radius (for example, 50 miles) were drawn around each plant. Define a neighboring establishment to be any establishment that is located within this circle, i.e. within 50 miles as the crow flies. Next calculate purchased inputs as a percentage of output at each plant. The data are now ready to be used to determine the relationship between purchased-inputs intensity and the amount of neighboring employment.

The ideal data set just described is not publicly available. However, a substantial amount of data is distributed by the Census on a CD-ROM. This publicly available data permit an analysis that is surprisingly close to the one described above. Setting up this data involves two steps. The first step determines the neighboring employment of establishments. The second step squeezes out the maximum information possible about purchased inputs from the publicly available data.

\subsubsection{Neighboring Employment}

The Location of Manufacturing Plants file reports the number of establishments in each of seven employment size categories by four-digit industry and county. This is an establishment-level data set. For each one of the 368,896 manufacturing establishments existing in 1987, the data set provides information about the industry, the employment size, and the location of the establishment. Let $i_{e}$ denote the four-digit industry of establishment $e$, where $e$ indexes the 368,896 establishments in the data set. The employment variable and the location variable require more discussion.

The seven size categories for the number of employees are 1-19, 20-49, 50-99, 100-249, 250-499, 500-999, and 1000 or more. I converted this categorical variable to an estimate of the employment for each establishment. For each size class, I calculated the mean number of employees across all the establishments within the size class. (This information is available from aggregate data.) For example, in 
the 1-19 size class, the mean of employment is 6 while in the $20-49$ size class, the mean of employment is 31 . For each establishment $e$, define employment $t_{e}$ to be the mean number of employees within the establishment's size class. For example, if an establishment is in the 1-19 size class, employment $t_{e}=6$, and if it is in the 20-49 size class, employment $=31 .^{15}$

The location information is the county that the establishment is in. I obtained the longitude and latitude of the geographic center of each county and used these coordinates to approximate the location of each establishment. Let longitude $e_{e}$ and latitude $e_{e}$ be the approximate longitude and latitude of establishment $e$.

With these approximations for the employment of each establishment and the location of each establishment, it is possible to approximate the level of neighboring employment for each establishment. As just mentioned, establishments are assigned the coordinates of the geographic center of the county they are located in. Hence, the neighbors of an establishment consist of establishments within the same county as well as establishments in nearby counties.

At this point it is useful to discuss some issues concerning distances between counties. For a given radius $r$, county $c$ is said to be a neighbor of county $c^{\prime}$ if the geographic center of county $c$ is less than $r$ miles away from the geographic center of county $c^{\prime}$. Consider the set of neighboring counties of county $c$. If the radius is small enough, the set of neighboring counties consists of the county itself. This would probably not look much like a circle of radius $r$. However, if $r$ is made large, the number of neighboring counties gets large, and together they begin to approximate a circle of radius $r$.

I selected a radius of 50 miles to use in the analysis. To get an idea of what the neighborhoods look like with such a radius, consider Figure 2. To create this figure I selected a random sample of counties spaced 150 miles apart (the gray counties in the figure). For each of these counties I determined the neighboring counties (the black counties in the figure). In the midwestern and eastern parts of the country, the neighborhoods look something like circles with a radius of 50 miles. In states like Nevada and Arizona, the neighborhoods look nothing like such circles because

\footnotetext{
${ }^{15}$ Mean employment in the 1000 or more size class varies substantially across industry. For this size class, the mean within the two-digit industry was used.
} 
the counties are so large. (Several of the counties in these states are bigger then New Jersey.) Fortunately (for my purposes) there are relatively few establishments in states like Nevada.

One way to test how well these neighborhoods approximate a 50-mile-radius circle is to examine how the surface areas of these neighborhoods compare with the area of a 50-mile-radius circle. A difficulty arises with establishments near an ocean or a foreign country. When a circle is drawn around such an establishment, part of the circle ends up in the water or on foreign territory, and the area is not counted. To avoid this difficulty, I considered the subset of the establishment population located in states that do not border any oceans, great lakes, Mexico, or Canada (a description which fits 14 states). (Note I look at interior states only for this exercise; in the rest of the analysis I use all the states.) When a circle of radius 50 miles or less is drawn around establishments in interior states, all of the points in the circle lie within counties in the United States. For each such establishment, I calculated the area of the counties in the neighborhood of the establishment and divided it by the area of a circle with radius 50 miles. Call this ratio the relative area. For establishments in interior states, the median relative area of the neighboring counties equals 1.01; i.e., the area of the neighborhood virtually equals the area of a circle of radius 50 . The 25th percentile is 0.94 , and the 75 th percentile is 1.08 . Hence, the distribution is relatively tight around 1 .

I considered using radii of less than 50 miles, but the neighborhoods looked much less like circles of a fixed radius. For example, with a radius of 10 miles, the neighborhood of most establishments consists only of the county the establishment is located in. Obviously, for some geographic analysis a shorter distance than a 50-mile radius would be appropriate. (For example, 100 feet might be appropriate for analyzing spillovers in a retail shopping mall.) However, the geographic detail here is too crude to handle very short distances. It appears adequate to handle a distance of 50 miles.

For each establishment $e$, define neighbor $e_{e}^{o w n}$ to be the total employment of neighboring establishments (those located within 50 miles) that are in the same four-digit industry as establishment $e$. This is own-industry neighboring employment. Note that this variable does not include the employment of establishment $e$ - it is the em- 
ployment outside of this factory located nearby. The variable is calculated using the estimates for the employment of each establishment described above. A second variable neighbor $e_{e}^{\text {rel }}$ is related-industry neighboring employment. This is employment of neighboring establishments within the same two-digit industry as establishment $e$

but outside of the same four-digit industry. A third variable neighborother is othermanufacturing neighboring employment. This includes all neighboring manufacturing employment except for employment within the same two-digit industry as establishment $e$. All neighboring employment of establishment $e$ is in one of the three mutually exclusive categories: own-industry, related-industry, or other-manufacturing.

\subsubsection{Purchased Inputs and Output}

The variables purchased inputs and output are not publicly available at the establishment level. The Census publishes aggregates for the entire United States and for selected areas. These areas can be states, metropolitan statistical areas, and counties. Selected areas vary for different industries. For example, for the creamery butter industry $(\mathrm{SIC}=2021)$ these data are available for the state of Wisconsin as well as for the United States but for no other geographic area. However, for the commercial printing industry $(\mathrm{SIC}=2752)$ these data are available for over 200 geographic units.

For each industry, I used the data available from the Census to partition the set of counties in the United States into nonoverlapping areas for which it is possible to determine aggregate purchased inputs and output for the establishments in the area. For example, there are two areas for the creamery butter industry, the first being Wisconsin and the second being all of the United States except Wisconsin. (The data for the latter are obtained by subtracting the Wisconsin totals from the U.S. totals). For some industries I created areas that consisted of the balance of the counties in a state (when I had data on the state and some counties in the state) and other areas that consisted of the balance of the counties in a metropolitan statistical area (MSA) (when I had data on the MSA and some of the counties in the MSA).

Let $i a$ index a particular industry $i$ in a particular area $a$. Let purchased inputs $s_{i a}$ and output $t_{i a}$ denote the totals for these variables obtained by summing over the levels of the variables for all establishments in industry $i$ and area $a$. 


\subsubsection{The Industry/Area Data Set}

The industry/area data set is obtained by combining the purchased inputs and output data for each industry/area just described with the establishment-level data on neighboring employment described earlier.

The establishment-level data have to be aggregated up to the level of an industry/area in some way. Here is the procedure that I used. Note first that purchasedinputs intensity in an industry/area can be written as the weighted sum of purchasedinputs intensity at the establishment level,

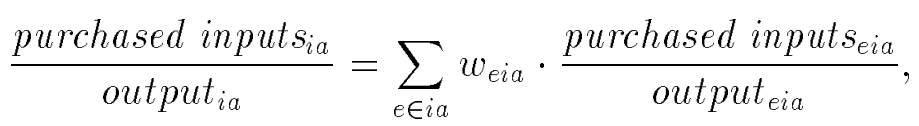

with the weights given by the establishment share of industry/area output,

$$
w_{e i a} \equiv \frac{\text { output }_{\text {eia }}}{\text { output }_{\text {ia }}}
$$

This suggests an aggregation of the neighboring employment data that uses establishment output share as weight. Unfortunately, I do not observe establishment output share. However, an establishment's output share is likely to be closely related to its employment share, and I can construct an estimate of establishment employment share by

$$
\widehat{w}_{e i a} \equiv \frac{\text { employment }}{\text { emplayment }} \text { em }
$$

Now define average own-industry neighboring employment in industry/area ia by

$$
\text { neighbor }{ }_{i a}^{o w n} \equiv \sum_{e \in i a} \hat{w}_{e i a} \cdot \text { neighbor }{ }_{\text {eia }}^{o w n} \text {. }
$$

Average related-industry employment neighbor ${ }_{i a}^{\text {related }}$ and average other-manufacturing employment neighbor ${ }_{i a}^{\text {other }}$ are defined in an analogous way.

Table 1 presents some summary statistics of the industry/area data set. The first part of the table (part A) reports the distribution of the number of areas across industries. There are 26 industries with only one area. (The Census only reports data for the entire United States for these industries.) These industries will be deleted in the analysis below because there is no cross-section variation across areas within these industries. After the records for the 26 industries with only one area are deleted, there 
remain 8096 industry/areas. Part B of Table 1 reports the means of selected variables over these 8096 industry/areas.

There is one additional variable in the data set left to explain. The analysis makes distinctions between industries based on the extent to which the industries are geographically concentrated. In a recent paper, Ellison and Glaeser (1994) have developed what they call a "dartboard approach" to measuring geographic concentration of industry. Ellison and Glaeser note that even if location decisions were completely random, some geographic concentration of employment would be expected if there are only a few plants in the industry. For example, we should not be surprised to learn that all the employment in an industry is concentrated within two states if we already know that there are only two establishments in the industry. As another example, if 100 plants are randomly assigned to 100 locations, it is likely that some locations would be assigned more than one plant. Ellison and Glaeser develop a measure of concentration that distinguishes a true tendency toward geographic concentration from the concentration that would be expected to occur due to randomness and a small number of establishments in the industry. They use the 1987 Census of Manufactures to calculate this measure, and they report the index for all four-digit manufacturing industries. I use their index to classify industries, and I call it the Ellison-Glaeser index.

\section{Empirical Results}

This section examines the relationship between purchased-inputs intensity and geographical concentration of industry. The first part of this section presents some preliminary numbers calculated in a simple way that avoids the complicated treatment of the geographical data explained in the previous section. The second part of this section uses the industry/area data set described in the previous section to examine the issues.

\subsection{Some Preliminary Numbers}

Table 2 provides a simple way to consider the relationship between purchased-inputs intensity and geographic concentration of industry. For this table I chose the 20 
industries with the highest Ellison-Glaeser indices of concentration. ${ }^{16}$ The industries are listed in descending order according to the index. Define the center of the industry to be the state with the highest share of employment in the industry. For example, the fur industry has the highest value of the Ellison-Glaeser index. The state of New York is the center of this industry, and New York contains 77 percent of all of the employment in this industry. For all of the industries listed, the center's share of industry employment is quite high.

The table reports purchased-inputs intensity for establishments located within the state that is the center of the industry as well as for establishments located outside of this state. For example, in the fur industry, purchased inputs equal 71 percent of output in New York, but only 60 percent of output outside New York. In the wine industry, purchased inputs equal 58 percent of output in California, but only 54 percent of output outside of California. In 16 of the 20 industries, purchased-inputs intensity is greater within the state that is the center of the industry than outside of this state. (The 4 exceptions are are highlighted.) Hence, for an overwhelming majority of the industries the predicted pattern holds.

To give some sense of the statistical significance of this finding, consider a null hypothesis that for a randomly selected industry the probability is one-half that the intensity measure is greater inside the center than outside it. Then, for a sample of 20 industries, the probability of drawing 16 or more industries in which the measure is greater in the center is only .006 (the probability of drawing 16 or more heads in 20 flips of a fair coin). Hence, this null hypothesis can be soundly rejected.

\subsection{The Findings With the Industry/Area Data Set}

I now consider the relationship between purchased-inputs intensity and neighboring employment. I begin with some simple linear regression models. I then consider a nonlinear model that allows for a number of different size groupings.

The procedure allowed for industry fixed effects by differencing the left-side variable and the right-side variables by industry means. The procedure regressed the av-

\footnotetext{
${ }^{16}$ More precisely, I chose the top 20 industries for which the data required by the table are available. This eliminates several industries which would otherwise be in the table: jewelers' materials, guided missiles, chewing and smoking tobacco, and primary copper.
} 
erage level of the purchased-inputs intensity in an industry/area (differenced from the industry mean) against the average levels of neighboring employment variables (also differenced from industry means). I used weighted least squares, with the weights given by the number of establishments in an industry/area and with a correction to take into account the asymmetry of establishment size among establishments within an industry/area. This procedure is explained in the appendix. The motivation for using this procedure is that under certain assumptions it identifies what the parameter estimates would be if I were to run the same regressions with establishment-level data (as opposed to the industry/area-level data that are actually used).

\section{Linear Models}

Table 3 presents a variety of linear regression models. The regression in the first row includes only own-industry neighboring employment on the right-hand side. (There is no constant term because the industry fixed effects are taken out.) All the neighboring employment levels are denoted in units of 1,000 employees. The estimated coefficient on own-industry neighboring employment in the first model is .04. Given that the estimated standard error is .01, the coefficient is significantly different from zero in the usual statistical sense. The interpretation of the estimated coefficient is that in a cross-section of areas within an industry, the conditional expectation of purchased inputs as a percentage of output increases by .04 with an increase of 1,000 in own-industry neighboring employment in the area. (Under certain assumptions discussed in the appendix, the word "establishment" can be substituted for "area" in the previous statement.) To put such a change in employment in perspective, the standard deviation of own-industry neighboring employment across establishments is 7,000 employees. Within the same industry, own-industry neighboring employment can vary from zero for some establishments to 97,000 for other establishments. ${ }^{17}$ Note that while the conditional mean does depend upon own-industry neighboring employment, only a small fraction of the variation in purchased-inputs intensity can be accounted for by variations in neighboring employment. (The $R^{2}$ is only .001.)

The second regression in Table 3 includes neighboring related-industry employ-

\footnotetext{
${ }^{17}$ The upper bound 97,000 is higher than the 74,100 reported in Table $1 \mathrm{~B}$ because the latter figure is the average across establishments within an area.
} 
ment as a second right-hand side variable. The estimated coefficient estimate of the related-industry variable is zero, and the coefficient on own-industry neighboring employment stays the same. The third regression adds in neighboring othermanufacturing employment. The coefficient on own-industry neighboring employment increases slightly to .05. The coefficient on other manufacturing is actually slightly negative.

The theory of Section 2.4 implies that the relationship between purchased-inputs intensity and neighboring employment depends upon whether the industry is geographically concentrated or geographically dispersed. To investigate this issue, the set of 433 different four-digit industries in the industry/area data set was divided in half on the basis of the Ellison-Glaeser index. The median industry has an EllisonGlaeser index of .025. Those industries below the median are in the bottom half. Since these industries have a relatively low Ellison-Glaeser index, they can also be called dispersed industries. Analogously, industries in the top half can be called concentrated industries.

The results for these two industry subsets are found in the bottom two rows of Table 3. For dispersed industries (i.e., those in the bottom half) there is virtually no relationship between purchased-inputs intensity and own-industry neighboring employment. The coefficient estimate is only .01, and this is not statistically different from zero. The story is different for concentrated industries (those in the top half). The estimated coefficient is .10 , and it is statistically significant.

\section{Dummy Variable Models}

In the theoretical model there is a nonlinear relationship between purchased-inputs intensity and neighboring employment. One way to allow for a nonlinear relationship is to construct various size groupings and then use dummy variables.

Each establishment was classified into one of five groups based on the establishment's own-industry neighboring employment (in thousands): "Below .5," ".5 to 2.5," "2.5 to 10," "10 to 25," and "Above 25." On the basis of this classification, four dummy variables were constructed with "Below .5" being the excluded group. Thus, if an establishment is in the "Below .5" group, the four dummy variables are zero; if 
an establishment is in the ".5 to 2.5 " group, the first dummy variable is one and the remaining three are zero; and so on. These establishment-level dummy variables were aggregated by taking a weighted average over the establishments in a given industry and area as in $(20)$. Note that because of the nonlinearities here, this procedure which defines the dummy variables at the establishment level and then aggregates is different from (and preferable to) a procedure which defines dummy variables using the average neighboring employment in the industry/area, neighbor ${ }_{i a}^{\text {own }}$.

Analogous groupings were constructed for related-industry and other-manufacturing neighboring employment. These various groupings are displayed in Table 4. There are three sets of dummy variables corresponding to the three categories of neighboring employment (own-industry, related-industry, and other-manufacturing). For each set of dummy variables there is one excluded group, the left-most group within the category.

The first row of Table 4 reports the coefficient estimates for all industries combined. Note first the estimate of 1.2 on the own-industry dummy variable for "..5 to 2.5." This coefficient has the following interpretation. The average difference in purchased-inputs intensity between establishments in the ".5 to 2.5 " group and those in the "Below .5" group is 1.2. In calculating these differences, the industry of the establishments as well as the related-industry and other-manufacturing neighboring employment groups is held fixed. To place this change in perspective, recall that the average level of purchased-inputs intensity is around 50 percent.

Now consider the remaining coefficients in the first row of Table 4. The coefficients on own-industry neighboring employment are all statistically significantly different from zero. Furthermore, they monotonically increase as we move across the row, from 1.2 to 1.4 to 3.1 to 3.7 . This is consistent with the prediction from the theory that purchased-inputs intensity increases in the level of own-industry neighboring employment.

In contrast to the coefficients on the own-industry variables, the coefficients on the related-industry variables are all small and, for the most part, not significantly different from zero. The same is true for other-manufacturing, with the exception of the 1.8 coefficient for the " 10 to 25 " group. 
Now consider what happens in the last two rows, where separate regressions are computed for the bottom half and top half concentration subgroups. For the dispersed industries there is virtually no relation between own-industry neighboring employment group and purchased-inputs intensity. The coefficients on these variables are all small and not statistically different from zero. However, for concentrated industries the coefficients are all large. They increase as we move across the row from 2.0 to 2.2 to 5.7 to 6.6 . These numbers are large in a statistical sense. (They are all significant at the .1 percent level.) They are also large in an economic sense. Since purchased-inputs intensity averages about 50 percent, an increase of 6.6 points is a percentage increase of around 13 percent.

\section{Finer Industry Groupings}

Tables 3 and 4 report a stark result. When the average is taken across all the industries in the bottom half of the concentration index, the relationship between purchased-inputs intensity and own-industry employment within an industry is zero. In contrast, when the average is taken over industries in the top half of the index, the relationship is strongly positive. Since this result is an important one for this analysis, it is worthwhile to explore it in more detail. In particular, it is useful to ask what happens when finer industry grouping are considered.

I divided the set of 433 industries into 10 subgroups, each with 43 or 44 industries. As before, the industries are ranked according to the Ellison-Glaeser concentration index. Group 1 consists of the industries in the bottom decile of this index, group 2 is the second decile, and so on.

When the industry/area data set is broken up in this way, there are considerably fewer observations in the industry subsets than in the earlier analysis. For some of these industry subsets, there are no observations in some of the own-industry size classes. For example, for the industries in decile 3 and decile 4 , there exists no establishment with own-industry neighboring employment in either the "10 to 25" group or the "Above 25" group. This situation led me to combine some of the own-industry neighborhood employment size groupings. Here a finer classification of industries is employed at the expense of a cruder definition of own-industry neighboring employ- 
ment.

I considered four different ways to define the groups. These four different ways correspond to the four different columns of Table 5 .

The first regression uses two own-industry neighboring employment groupings: "Below .5" and "Above .5" This regression and the ones to follow all use the same dummy variables for related-industry and other-manufacturing neighboring employment as used in Table 4. (The results are the similar if these controls are eliminated.) The first column of Table 5 reports the coefficient estimates on the "Above .5" variable for all the industries combined and for the various industry deciles.

The second regression uses three own-industry neighboring employment groupings: "Below .5," ".5 to 1," and "Above 1." The "Below .5" group is the excluded group in the regression. The second column of Table 5 reports the coefficients on the "Above 1" group for all industries combined and for the various deciles. The third and fourth regressions are analogous to the second except the groupings are "Below .5," ".5 to 2.5," and "Above 2.5." in the third and "Below .5," ".5 to 5," and "Above 5" in the fourth. Note that the excluded group is the same (the "Below .5" group) for all four different regressions.

Each coefficient in Table 5 is as an estimate of the average difference in purchasedinputs intensity within an industry between the level when own-industry neighboring employment is above some threshold and when the level is below .5 (thousand). As we move from left to right, the threshold increases. For the "All Industries" case in the first row, the estimated difference increases as we move from left to right, which is consistent with the earlier results.

The main interest here is how the estimated differences vary across the industry concentration deciles, i.e., what happens as we move down a column. Consider the first column. There is a fairly clear pattern here that the estimated difference tends to increase as we move down the column. For example, in the first three deciles the coefficient is no higher than .6 while in the top four deciles the coefficient is no lower than 1.4. The pattern is monotonic from decile 5 to decile 10 . The other columns display a similar pattern. One exception to the pattern is that the estimated difference for decile 3 is relatively high in the third and fourth columns. Nevertheless, 
there is a clear pattern that the estimate tends to be close to zero in the low deciles and positive in the high deciles. This is consistent with the earlier finding that the estimated difference is zero in the bottom half industries and positive in the top half industries.

One issue that can be raised at this point is how the distribution of own-industry neighboring employment varies across the industry concentration groups. The average establishment in a geographically concentrated industry has more neighboring ownindustry employment than the average establishment in a geographically dispersed industry. Suppose that expected purchased-inputs intensity were strictly increasing in own-industry neighboring employment, and suppose that this relationship were actually the same across all industries. If this were the case and we ran the regression of the first column of Table 5, we would expect the estimated coefficients for the low-decile industries to be lower than the coefficients for the high-decile industries because of the higher average neighboring employment in the high-decile industries. However, we also would expect that, for both low decile and high decile industries, the estimated coefficients would increase as we move from left to right across each row. While this is true for decile 3 , it is certainly not true for deciles $1,2,4$, and 5 . Hence, the results of Table 5 are inconsistent with the relationship between purchased-inputs intensity and own-industry neighboring employment being the same for all industries.

\section{Conclusion}

This paper asks two questions. First, is the organization of production in an industry more vertically disintegrated in areas where an industry is concentrated compared to areas where an industry has only a small presence? Second, is the increased opportunity for specialization found in an industrial district a relevant factor explaining the location of industry?

To address the first question, I constructed a measure of purchased-inputs intensity and a measure of neighboring employment of establishments. I found that within an industry there is a positive association between these two variables. This suggests that there is vertical disintegration in an industrial district compared to establishments in the same industry in isolated areas. 
To address the second question, I distinguished between industries that are geographically concentrated and those that are dispersed. I found that, in dispersed industries, there is virtually no relationship between purchased-inputs intensity and neighboring employment. In concentrated industries, there is a relatively strong positive relationship. I presented a theory that implies that this is what should happen if increased opportunity for specialization is a factor in the localization of industry.

The analysis of this paper is subject to a number of qualifications and caveats. An obvious difficulty is that the purchased-inputs intensity measure defined in this paper is a rather crude way to measure vertical disintegration. Limitations of this variable were recognized by Adelman (1955) and elaborated upon in the comment by Barnes (1955). In particular, if a plant specializes at an early stage of production (such as raw material extraction), it will have a low value of purchased-inputs intensity even though the plant is not vertically integrated. While this problem certainly adds noise, I do not see how the problem adds any systematic bias in the application of this variable used here.

A weak point of the analysis is the treatment of establishments from geographically concentrated industries that are located in isolated areas. According to the simplest version of the theory, in such an industry all the establishments will locate in a single area. I motivate the existence of isolated establishments by appealing to a notion of a demand for locally produced goods or a supply from an immobile factor in the area. This may be reasonable as a first step. However, it must be recognized that plants in isolated areas might make different kinds of products than plants in concentrated areas even though the industry is formally the same according to the Census. For example, it is well known that dresses manufactured in New York (where the industry is centered) are likely to be more fashion-oriented than dresses manufactured outside of New York. 


\section{Appendix: The Regression Procedure}

This appendix presents a simple statistical model to motivate the empirical procedure that was employed. Consider a statistical process that operates at the level of each establishment. Suppose that the purchased-inputs intensity of establishment $e$ in industry $i$ in area $a$ equals a linear function of the neighboring own-industry employment of the establishment plus a random variable:

$$
\frac{\text { purchased inputs }_{e i a}}{\text { output }_{\text {eia }}}=\alpha_{i}+\beta_{i} \text { neighbor } \text { ewn }_{\text {eia }}+\epsilon_{\text {eia }} \text {. }
$$

The first term $\alpha_{i}$ is a constant that may vary by industry. The second term is the product of a coefficient $\beta_{i}$ that varies by industry and the level of own-industry neighboring employment of the establishment. The third term $\epsilon_{\text {eia }}$ is the difference between the realization of purchased-inputs intensity for the establishment and the conditional mean. Assume that $\epsilon_{e i a}$ is i.i.d. throughout the universe of establishments and suppose the variance is $\sigma^{2}$.

The average purchased-inputs intensity for establishments in industry/area ia equals the mean of purchased inputs use across establishments in the area with weights equal to the output shares of the establishments. Therefore, using (21), the average purchased-inputs intensity in industry/area $i a$ can be written as

$$
\frac{\text { purchased inputs }_{i a}}{\text { output }_{i a}}=\alpha_{i}+\beta_{i} \text { neighbor own }+\epsilon_{i a},
$$

where $\epsilon_{i a}$ is the weighted sum of the establishment disturbances in the industry/area,

$$
\epsilon_{i a} \equiv \sum_{\epsilon \in i a} w_{e i a} \epsilon_{e i a},
$$

with the weights equal to the output shares $w_{\text {eia }}$ of the establishments, defined in the text by equation (18). The variance of $\epsilon_{i a}$ relative to the variance of the establishmentlevel disturbances equals

$$
\frac{\sigma_{i a}^{2}}{\sigma^{2}}=\sum_{e \in i a} w_{e i a}^{2} .
$$

With the industry/area data set, the parameters $\alpha_{i}$ and $\beta_{i}$ can be estimated using weighted least squares, with each observation weighted by the inverse of the relative 
variance (24). As discussed in the text, the actual output share $w_{e i a}$ is not observed, so instead I used the estimated employment share $\widehat{w}_{\text {eia }}$ defined by equation (19). I then plug these estimated employment shares into equation (24) to obtain an estimate of the relative variance and use the inverse as the weight in the weighted least squares procedure.

Consider the hypothesis that all the industries in a certain group of industries have the same slope term but can vary in the intercept term; i.e. $\beta_{i}=\beta$ for all industries $i$ in this group, but $\alpha_{i} \neq \alpha_{i^{\prime}}$ can happen for $i \neq i^{\prime}$. In this case, the parameter $\beta$ can be estimated by differencing the data by the industry means of each variable using as weights the inverse of the relative variance (24). I differenced the data in this way and used the differenced data for all of the analysis. This procedure removes the industry fixed effect $\alpha_{i}$ from the data. Because of this differencing of the data, no constant terms are reported. 


\section{References}

Abdel-Rahman, Hesmam (1988), "Product Differentiation, Monopolistic Competition and City Size," Regional Science and Urban Economics 18, 69-86.

Abdel-Rahman, Hesmam, and Masahisa Fujita (1990), "Product Variety, Marshallian Externalities, and City Sizes," Journal of Regional Science 30, 165-183.

Adelman, M.A. (1955), "Concept and Statistical Measurement of Vertical Integration," in G.J. Stigler, editor, Business Concentration and Price Policy, Princeton, N.J.: Princeton University Press, pp. 281-322.

Allen, G.C. (1929), The Industrial Development of Birmingham and the Black Country, 1860-1927, London: Allen and Unwin.

Barnes, Irston R., (1955), "Comment," in G.J. Stigler, editor, Business Concentration and Price Policy, Princeton, N.J.: Princeton University Press, pp. 322-330.

Ciccone, Antonio, and Robert E. Hall (1993), "Productivity and the Density of Economic Activity," National Bureau of Economic Research, Working Paper No. 4312.

Dixit, A., and J.E. Stiglitz (1977), "Monopolistic Competition and Optimum Product Diversity," American Economic Review 67, 297-308.

Ellison, Glenn, and Edward Glaeser (1994), "Geographic Concentration in U.S. Manufacturing Industries: A Dartboard Approach," National Bureau of Economic Research, Working Paper No. 4840.

Glaeser, Edward L., Hedi D. Kallal, José A. Scheinkman, and Andrei Shleifer (1992), "Growth in Cities," Journal of Political Economy 100, 1126-1152.

Goodfriend, Marvin, and John McDermott (1995), "Early Development," American Economic Review 85, 116-133. 
Hall, Max (1959), Made in New York: Case Studies in Metropolitan Manufacturing, Cambridge, Mass.: Harvard University Press.

Helfgott, Roy B. (1959) "Woman's and Children's Apparel," in Max Hall, editor, Made in New York: Case Studies in Metropolitan Manufacturing, Cambridge, Mass.: Harvard University Press.

Henderson, J. Vernon (1986), "Efficiency of Resource Use and City Size," Journal of Urban Economics 19, 47-70.

Jaffe, Adam B., Manuel Trajtenberg, and Rebecca Henderson (1993), "Geographic Localization of Knowledge Spillovers as Evidenced by Patent Citations," Quarterly Journal of Economics 108, 577-598.

Krugman, Paul (1991), Geography and Trade, Cambridge, Mass.: MIT Press.

Lichtenberg, Robert M. (1960), One-Tenth of a Nation: National Forces in the Economic Growth of the New York Region, Cambridge, Mass.: Harvard University Press.

Locay, Luis (1990) "Economic Development and the Division of Production between Households and Markets," Journal of Political Economy 98, 965-982.

Marshall, Alfred (1920), Principles of Economics, 8th ed., London: Macmillan.

Perry, Martin K. (1989), "Vertical Integration: Determinants and Effects," in Handbook of Industrial Organization, editors Richard Schmalensee and Robert Willig, Volume 1, Amsterdam: North-Holland.

Perry, Martin K., and R.H. Groff (1982), "Vertical Integration and Growth: An Examination of the Stigler Story," Bell Laboratories Economic Discussion Paper No. 257.

Scott, Allen J. (1983), "Location and Linkage Systems: A Survey and Reassessment," Annals of Regional Science 17, 1-39. 
Scott, Allen J., and E.C. Kwok (1989), "Inter-Firm Subcontracting and Locational Agglomeration: A Case Study of the Printed Circuits Industry in Southern California," Regional Studies 25, 405-416.

Scott, Allen J., and Doreen J. Mattingly (1989), "The Aircraft and Parts Industry in Southern California: Continuity and Change from the Inter-War Years to the 1990s," Economic Geography 65, 48-71.

Smith, Adam (1776), The Wealth of Nations, reprinted by University of Chicago Press, Chicago, 1976.

Stigler, George J. (1951), "The Division of Labor is Limited by the Extent of the Market," Journal of Political Economy, 59, 185-93.

Vassilakis, S. (1986), "Increasing Returns and Strategic Behavior," Ph.D. Dissertation, Department of Economics, Johns Hopkins University. 
Figure 1

The Number of Different Intermediate Inputs Available From Specialists

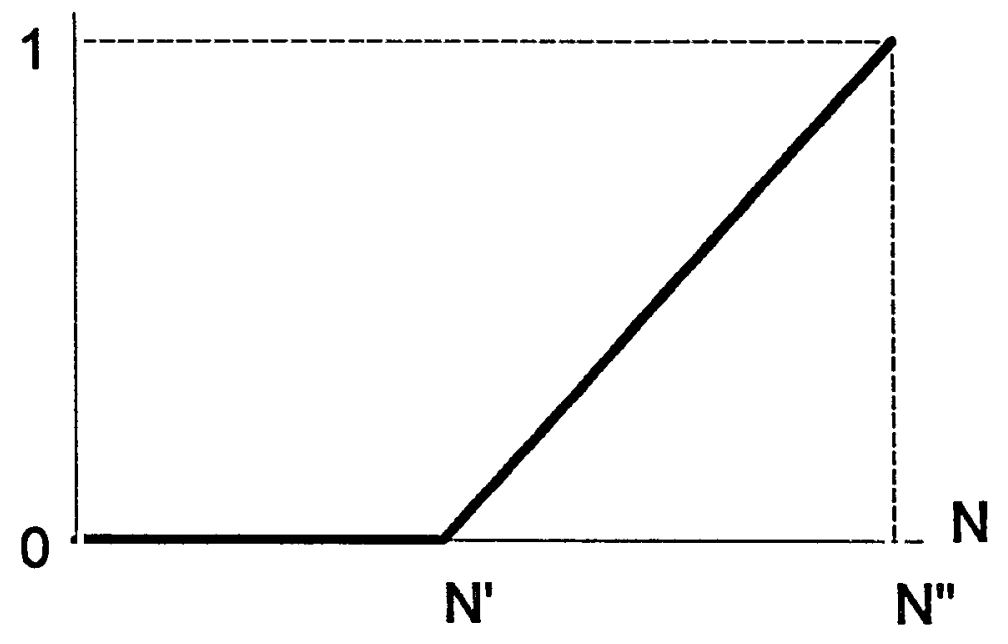


Figure 2

A Sample of Counties and Their Neighborhoods

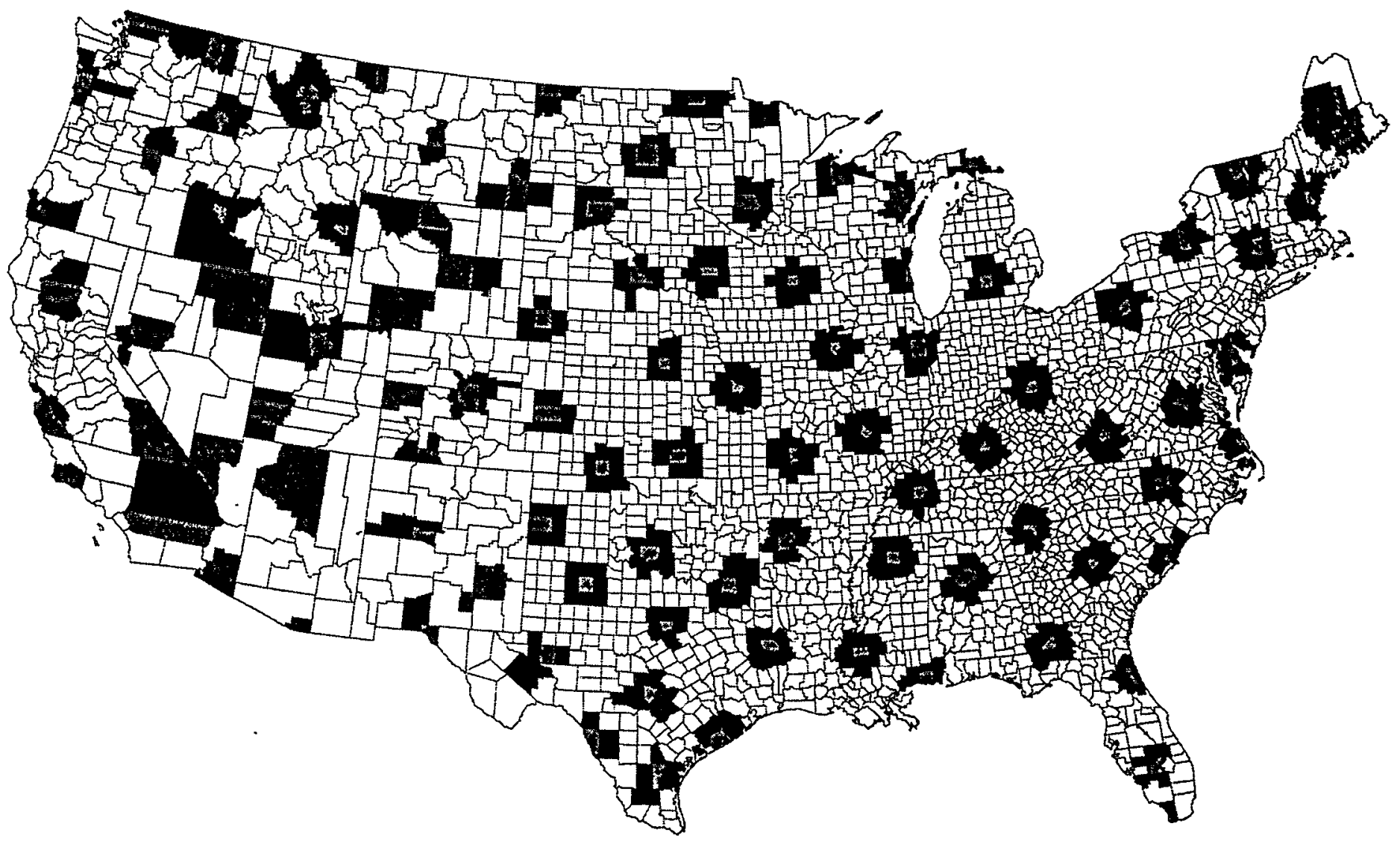

Center county

Neighboring counties 
Table 1

Industry/Area Data Set

Summary Statistics

A. Distribution of Number of Areas Across Industries

\begin{tabular}{rc}
\hline Number of Areas & $\begin{array}{c}\text { Number of Industries } \\
\text { With This Number of } \\
\text { Areas }\end{array}$ \\
& 26 \\
$2-5$ & 110 \\
$6-10$ & 99 \\
11 or More & 224 \\
\hline & \\
Subset of Industries With Multiple Areas & \\
\hline Number of Industries & 433 \\
Number of Industry/Areas & 8096 \\
\hline
\end{tabular}

B. Summary Statistics of Selected Area Variables

\begin{tabular}{|c|c|c|c|c|c|}
\hline Description & Notation & Mean & $\begin{array}{l}\text { Std. } \\
\text { Dev. }\end{array}$ & Min. & Max. \\
\hline Number of Establishments & number $_{i a}$ & $\overline{44.2}$ & 102.7 & 1 & 4226 \\
\hline Employment (thousands) & employment $_{i a}$ & 2.1 & 5.7 & 0.01 & 216.5 \\
\hline Purchased-Inputs Intensity & $100 \times \frac{\text { purchased-inputs }}{\text { output }}$ & 47.3 & 14.0 & 1.9 & 102.9 \\
\hline \multicolumn{6}{|c|}{$\begin{array}{l}\text { Neighboring Employment Measures } \\
\text { (thousands of employees) }\end{array}$} \\
\hline Own-Industry & neighbor $r_{i a}^{\text {own }}$ & 2.3 & 4.7 & 0 & 74.1 \\
\hline Related-Industry & neighbor realed & 25.4 & 31.6 & 0 & 195.2 \\
\hline Other-Manufacturing & neighbor $r_{i a}^{\text {other }}$ & 315.3 & 320.3 & 0 & 1178.9 \\
\hline
\end{tabular}


Table 2

Purchased-Inputs Intensity for Localized Industries

\begin{tabular}{|c|c|c|c|c|c|c|}
\hline \multicolumn{2}{|c|}{ Four-Digit Industry } & \multirow[t]{2}{*}{$\begin{array}{l}\text { Ellison- } \\
\text { Glaeser } \\
\text { Index }\end{array}$} & \multirow{2}{*}{ Center } & \multirow{2}{*}{$\begin{array}{l}\text { Center } \\
\text { Share of } \\
\text { Employees } \\
\quad(\%)\end{array}$} & \multicolumn{2}{|c|}{$\begin{array}{l}\text { Purchased-Inputs } \\
\text { Intensity } \\
(\%)\end{array}$} \\
\hline & & & & & Center & $\begin{array}{c}\text { Rest of } \\
\text { U.S. } \\
\end{array}$ \\
\hline 2371 & Fur Goods & .63 & New York & 77 & 71 & 60 \\
\hline 2084 & Wines, Brandy, Brandy Spirits & .48 & California & 78 & 58 & 54 \\
\hline 2252 & Hosiery, n.e.c. & .44 & North Carolina & 66 & 51.6 & 51.9 \\
\hline 3533 & Oil Field Machinery & .43 & Texas & 66 & 47 & 42 \\
\hline 2251 & Women's Hosiery Except Socks & .40 & North Carolina & 62 & 53 & 40 \\
\hline 2273 & Carpets and Rugs & .38 & Georgia & 62 & 73 & 62 \\
\hline 2429 & Special Product Sawmills, n.e.c. & .37 & Washington & 59 & 59 & 55 \\
\hline 3961 & Costume Jewelry & .32 & Rhode Island & 54 & 40 & 36 \\
\hline 2895 & Carbon Black & .30 & Texas & 39 & 56 & 53 \\
\hline 2874 & Phosphatic Fertilizers & .29 & Florida & 54 & 68 & 70 \\
\hline 2061 & Raw Cane Sugar & .29 & Hawaii & 32 & 46 & 71 \\
\hline 2281 & Yarn Spinning Mills & .28 & North Carolina & 49 & 58 & 61. \\
\hline 2034 & Dehydrated Fruits & .28 & California & 59 & 57 & 41 \\
\hline 2083 & Malt & .24 & Wisconsin & 43 & 69.4 & 69.2 \\
\hline 2221 & Weaving Mills, Synthetics & .23 & South Carolina & 41 & 57 & 55 \\
\hline 2284 & Thread Mills & .21 & North Carolina & 46 & 65 & 60 \\
\hline 2282 & Throwing and Winding Mills & .21 & North Carolina & 40 & 79 & 68 \\
\hline 2257 & Circular Knit Fabric Mills & .19 & North Carolina & 44 & 65 & 57 \\
\hline 2262 & Finishing Plants Synthetics & .19 & South Carolina & 39 & 76 & 70 \\
\hline 2436 & Sof:wood Veneer and Plywood & .19 & Oregon & 38 & 62 & 59 \\
\hline
\end{tabular}


Table 3

Purchased-Inputs Intensity and Neighboring Employment

Regression Estimates for Various Linear Models

(Neighboring Employment in 1,000s)

\begin{tabular}{|c|c|c|c|c|c|}
\hline & \multicolumn{3}{|c|}{ Average Neighboring Employment } & \multirow[t]{2}{*}{$\mathrm{R}^{2}$} & \multirow{2}{*}{$\begin{array}{l}\text { Number of } \\
\text { Observations }\end{array}$} \\
\hline & Own -Industry & $\begin{array}{l}\text { Related - } \\
\text { Industry }\end{array}$ & $\begin{array}{c}\text { Other- } \\
\text { Manufacturing }\end{array}$ & & \\
\hline \multirow[t]{3}{*}{ All Industries } & $\begin{array}{c}.04 \\
(.01)\end{array}$ & - & - & .001 & 8096 \\
\hline & $\begin{array}{c}.04 \\
(.02)\end{array}$ & $\begin{array}{l}.000 \\
(.003)\end{array}$ & - & .001 & 8096 \\
\hline & $\begin{array}{l}.05 \\
(.02)\end{array}$ & $\begin{array}{l}.009 \\
(.004)\end{array}$ & $\begin{array}{l}-.0013 \\
(.0004)\end{array}$ & .002 & 8096 \\
\hline \multicolumn{6}{|c|}{$\begin{array}{l}\text { Industries Broken up by } \\
\text { Concentration }\end{array}$} \\
\hline Bottom Half & $\begin{array}{c}.01 \\
(.02)\end{array}$ & $\begin{array}{l}-.003 \\
(.005)\end{array}$ & $\begin{array}{l}-.0017 \\
(.0004)\end{array}$ & .010 & 5295 \\
\hline Top Half & $\begin{array}{c}.10 \\
(.03)\end{array}$ & $\begin{array}{c}.020 \\
(.008)\end{array}$ & $\begin{array}{c}.0012 \\
(.0008)\end{array}$ & .031 & 2801 \\
\hline
\end{tabular}

Note: Numbers in parentheses are standard errors. 
Table 4

Purchased-Inputs Intensity and Neighboring Employment

Regression Estimates for Dummy Variable Model

(Neighboring Employment in 1,000s)

\begin{tabular}{|c|c|c|c|c|c|c|c|c|c|c|c|c|c|c|c|c|}
\hline & \multicolumn{15}{|c|}{ Dummy Variables for Neighboring Employment Size Classes } & \multirow[t]{3}{*}{$\mathbf{R}^{2}$} \\
\hline & \multicolumn{5}{|c|}{ Own-Industry } & \multicolumn{5}{|c|}{ Related-Industry } & \multicolumn{5}{|c|}{ Other-Manufacturing } & \\
\hline & $0-.5$ & $\begin{array}{l}.5- \\
2.5 \\
\end{array}$ & $\begin{array}{l}2.5- \\
10 \\
\end{array}$ & $10-25$ & $25+$ & $0-2.5$ & $\begin{array}{c}2.5- \\
10 \\
\end{array}$ & $10-25$ & $\begin{array}{l}25- \\
100 \\
\end{array}$ & $100+$ & $0-10$ & $10-25$ & $\begin{array}{l}25- \\
100\end{array}$ & $\begin{array}{l}100- \\
500 \\
\end{array}$ & $500+$ & \\
\hline $\begin{array}{l}\text { All } \\
\text { Industries }\end{array}$ & $\mathbf{x}$ & $\begin{array}{l}1.2 \\
(.3)\end{array}$ & $\begin{array}{l}1.4 \\
(.4)\end{array}$ & $\begin{array}{l}3.1 \\
(.6)\end{array}$ & $\begin{array}{l}3.7 \\
(.8)\end{array}$ & $\mathbf{x}$ & $\begin{array}{c}.8 \\
(.4)\end{array}$ & $\begin{array}{c}.8 \\
(.5)\end{array}$ & $\begin{array}{c}.1 \\
(.6)\end{array}$ & $\begin{array}{l}1.0 \\
(.7)\end{array}$ & $\mathbf{x}$ & $\begin{array}{l}1.8 \\
(.9)\end{array}$ & $\begin{array}{c}.9 \\
(.6)\end{array}$ & $\begin{array}{l}-.2 \\
(.7)\end{array}$ & $\begin{array}{r}-1.0 \\
(.7)\end{array}$ & .009 \\
\hline \multicolumn{17}{|c|}{ Industries Broken Up by Concentration } \\
\hline $\begin{array}{l}\text { Bottom } \\
\text { Half }\end{array}$ & $\mathbf{x}$ & $\begin{array}{l}.4 \\
(.4)\end{array}$ & $\begin{array}{c}.2 \\
(.5)\end{array}$ & $\begin{array}{l}1.0 \\
(.7)\end{array}$ & $\begin{array}{c}.4 \\
(1.0)\end{array}$ & $\mathbf{x}$ & $\begin{array}{l}1.5 \\
(.5)\end{array}$ & $\begin{array}{l}2.0 \\
(.5)\end{array}$ & $\begin{array}{l}1.2 \\
(.6)\end{array}$ & $\begin{array}{l}1.5 \\
(.9)\end{array}$ & $\mathbf{x}$ & $\begin{array}{l}4.3 \\
(1.2)\end{array}$ & $\begin{array}{c}3.6 \\
(1.0)\end{array}$ & $\begin{array}{c}1.2 \\
(1.0)\end{array}$ & $\begin{array}{c}-.3 \\
(1.0)\end{array}$ & .021 \\
\hline Top Half & $\mathrm{x}$ & $\begin{array}{l}2.0 \\
(.5)\end{array}$ & $\begin{array}{l}2.2 \\
(.7)\end{array}$ & $\begin{array}{c}5.7 \\
(1.0)\end{array}$ & $\begin{array}{c}6.6 \\
(1.2)\end{array}$ & $\mathbf{x}$ & 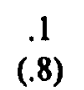 & $\begin{array}{l}-.0 \\
(.9)\end{array}$ & $\begin{array}{c}-.5 \\
(1.1)\end{array}$ & $\begin{array}{c}-.3 \\
(1.3)\end{array}$ & $\mathbf{x}$ & $\begin{array}{c}1.8 \\
(1.2)\end{array}$ & $\begin{array}{l}-.7 \\
(.9)\end{array}$ & $\begin{array}{c}1.0 \\
(1.1)\end{array}$ & $\begin{array}{c}1.8 \\
(1.2)\end{array}$ & .042 \\
\hline
\end{tabular}

Note: Numbers in parentheses are standard errors. 
Table 5

Coefficients on Own-Industry Neighboring Employment Dummies

Difference from Establishments in "Below .5" Group

\begin{tabular}{lcccc}
\hline & Above .5 & Above 1 & Above 2.5 & Above 5 \\
\hline All Industries & $.9 * *$ & $1.2^{* *}$ & $1.3^{* *}$ & $2.1^{* *}$ \\
By Industry & & & & \\
Concentration & & & & \\
Deciles & & & & \\
1 & .0 & -.4 & -1.4 & -.1 \\
2 & -.1 & .5 & .1 & .1 \\
3 & .6 & 1.2 & $3.2^{* *}$ & $5.4^{* *}$ \\
4 & 1.0 & .8 & .1 & .5 \\
5 & -.3 & -.3 & -1.8 & -2.9 \\
6 & .8 & 1.3 & 1.7 & 4.4 \\
7 & 1.4 & 1.9 & $3.7^{* *}$ & $6.2^{* *}$ \\
8 & 1.7 & $2.3^{*}$ & 1.7 & 2.3 \\
9 & 1.8 & 2.2 & 2.6 & 3.5 \\
10 & $3.6^{* *}$ & $3.8^{* *}$ & $3.1^{*}$ & $3.5^{*}$ \\
\hline
\end{tabular}

*Significant at 5 percent level.

**Significant at 1 percent level. 